\title{
MEMÓRIA, NOSTALGIA E PUBLICIDADE: 0 CASO DAS CAMISAS RETRÔ DE FUTEBOL
}

\section{MEMORY, NOSTALGIA AND \\ ADVERTISING: THE CASE OF RETRO FOOTBALL SHIRTS}

RichaRles SOUZA DE CARVALHO *
MARIA MARTA FURLANETTO **

RESUMO: Este trabalho, seguindo as coordenadas gerais da Análise de Discurso de linha francesa, apresenta uma leitura discursiva do fenômeno designado como retrô, não novo por sua própria história, mas que se mostra distintamente no decurso do tempo. Observamos no discurso publicitário a presença marcante dos elementos retrô, tanto em propagandas que vendem produtos e se valem de materialidades de caráter retrô, como em produtos que se constituem nessas materialidades. Explorando o cruzamento de categorias discursivas com noções das ciências sociais, o artigo tem como objetivo, a par de teorizar o efeito retrô - refletindo sobre discursividade, memória, história, imagem, instâncias da publicidade -, investigar o discurso publicitário como manifestação multissemiótica que lança mão do discurso retrô, exemplificando

\footnotetext{
* Docente da Unesc - Universidade do Extremo Sul Catarinense. E-mail: rsc@unesc.net.

** Docente da Unisul - Universidade do Sul da Santa Catarina. E-mail: mmarta@intercorp.com.br.
} 
seu efeito com uma peça de indumentária: a camisa de futebol. Buscamos mostrar, ainda, por que se pode considerar camisas de futebol como materialidade discursiva que amalgama itens textuais numa reinterpretação do passado; finalmente, é feita uma proposta de tipologia para o que estamos chamando de discurso da tradição.

PALAVRAS-CHAVE: Discurso. Memória. Retrô. Camisa de futebol.

ABSTRACT: This paper, under the general background of the French Discourse Analysis, presents a discursive reading of the phenomenon referred as retro, that is not new for its own history, but which appears distinctly in the course of the time. We observe in advertising discourse the strong presence of retro elements, both in advertisements that sell products and use material elements of retro type, as in products whose materialities constitute them. Exploring the intersection of discursive categories with notions of social sciences, this work aims at investigating the advertising discourse as a multisemiotic manifestation that uses retro discourse, taking as an example its effect with a piece of clothing: a football shirt - theorizing the retro effect and reflecting on discursivity, memory, history, image, instances of advertising. We tried to show, yet, why football shirts can be considered as discursive materiality that amalgamates textual items within a reinterpretation of the past; eventually, it is done a proposal of typology for what we are conceptualizing as tradition discourse.

KEYWORDS: Discourse. Memory. Retro. Football shirt. 
Deleuze n'est pas un philosophe comme les autres, il est un passeur, il est un transmetteur par rapport aux autres philosophes de l'histoire de la philosophie. Il fait du nouveau avec de l'ancien...

Romain Sarnel, "Lieux de passages et transversalités: Pour une dynamique deleuzienne"

\section{Contextualização}

Para dizer que caminho seguiremos, tomemos esta historieta fictícia:

Noite de quarta-feira. Tradicional momento do futebol na televisão aberta brasileira. Dois grandes clubes de futebol aparecem na televisão em partida por determinado campeonato. Um grupo de pessoas assiste e pode-se ouvir o seguinte diálogo: "Mas que camisa diferente essa do Corinthians!" "É uma edição retrô de 77." "Puxa, já ouvi meu pai falando desse ano - o ano que nunca acabou". "Verdade, apesar dos grandes craques da década de 80, foi em 77 que o Timão ganhou um título após muitos anos sem nada". "Vou procurar essa camisa amanhã pra comprar."

Muitos podem familiarizar-se com o diálogo acima, pois em diversas instâncias estamos convivendo com elementos designados como retrô. Isso ocorre, sobretudo, na publicidade (como primeira vitrine para fazer ver), com a estratégia de venda, mas também em diversas outras esferas e em muitas situações cotidianas, que manifestam na concretude a vestimenta velha do novo, ou o antigo que se tornou vintage. Todas essas expressões e as categorias de que nos utilizamos merecem, adiante, atenção teórica. Temos de investir em sabe- 
res, subjetividade, história, memória, para propor uma leitura discursiva de um fenômeno não novo em sua própria história, mas que se mostra de modos distintos no decurso do tempo.

Para o retrô - termo originado nos anos 1960 na França, a partir de rétrograde - salienta-se que deve tratar-se de passado recente (OXFORD, 2014). Vintage tem sua origem no latim vindemia [v. port. vindima] - "remoção/colheita de vinho", passando ao francês antigo como vendange, de onde chegou ao inglês como vintage (OXFORD, 2014). Para o vinho, contudo, restringiu-se ao que seria de alta qualidade, e assim a qualificação se espalhou para tudo o mais que pudesse dizer-se ter uma qualidade especial. Hoje, aparelhos de som antigos, de alta fidelidade, são considerados vintage, não só pela raridade como pela qualidade sonora. Mas uma série de aparelhos novos que "imitam" designs antigos são classificados no próprio comércio como retrô.

Como se percebe, essas manifestações trazem em sua materialidade um apelo ao passado como viagem à memória coletiva, tanto quanto se revestem de uma aura de previsão direcionada para o futuro, tornando heterogênea essa eterna passagem que se chama presente, em que tudo se qualifica como novo sendo já velho. Ao mesmo tempo, faz-nos pensar nos contornos da humanidade, da subjetividade em constante passagem, buscando uma identidade que nunca se cristaliza - felizmente. Nisso, contudo, talvez a questão esteja em se pensar que o clima do passado (romantizado?) veio junto com o objeto que ressurgiu. Afinal, onde há memória há também seletividade, e esquecimento. Aquilo que se traz do passado sofre o processo de destacabilidade tal como o definiu Maingueneau (v. adiante), e que ajustaremos ao nosso propósito.

É senso comum dizer que vivemos em uma sociedade de alta tecnologia, das novidades, da efemeridade. Não conflituo- 
MEMÓRIA, NOSTALGIA E PUBLICIDADE: O CASO DAS CAMISAS RETRÔ DE FUTEBOL

samente, portanto, o velho e o novo coexistem - estamos sempre em passagem com entrelaçamentos. No entanto, em diversas situações, isso, apesar de presente, não é óbvio; as pessoas consomem essas representações retrô sem perceber, como na imagem abaixo, que apresenta uma capa para telefone celular que imita as desusadas fitas cassete. Essas capas são consumidas principalmente por jovens que sequer ouviram falar das fitas cassete, ou, se ouviram falar, nunca manusearam uma. Para a sua própria temporalidade, trata-se de uma novidade.

Imagem 1 - Capa retrô para aparelho celular

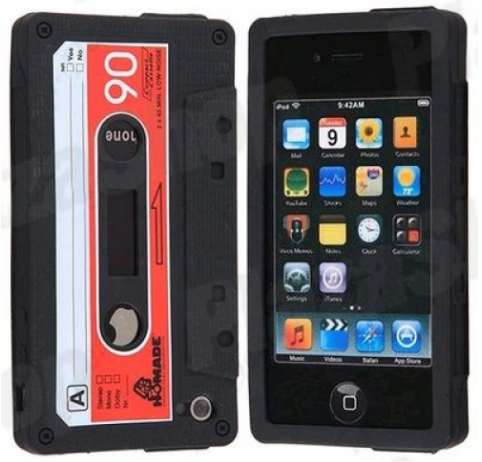

Fonte: Internet ${ }^{1}$

A efemeridade dos produtos, marcas, relacionamentos etc. por vezes é colocada à prova, como é o caso de fitas cassete, as quais, após alguns anos de hibernação e apesar de sua provável obsolescência, voltam ao mercado² ${ }^{2}$ Nessa mesma

1 Disponível em <http://www.plazzashop.com.br/capa-fita-cassete-retro-k7--iphone4-pronta-entrega-pac-gratis->. Acesso em: 16 out. 2014.

2 Disponível em: <http://www.duplication.ca/blank-cassettes-canada.htm> e <http:// oglobo.globo.com/cultura/fita-cassete-faz-50-anos-resiste-ao-digital-atraves-de-pequenos-selos-4417572>. Acesso em: 16 out. 2014. 
linha, é notável nos últimos anos o interesse pelos discos de vinil. Discretamente divulgado na grande mídia, desde 2009 uma fábrica (a única da América Latina ${ }^{3}$ ) de discos de vinil está em plena atividade no Rio de Janeiro. As opiniões divergem em relação à qualidade do som reproduzido por esses materiais, mas a verdade é que o artefato tão comum em outras décadas está sendo, mesmo que em pequena escala, consumido novamente.

Diversas marcas de eletrônicos já disponibilizam aparelhos que reproduzem os discos de vinil, como é o caso da Imagem 2. Mercadologicamente funciona com duplo ganho: para os que conheceram o design e a materialidade, é um retorno que se pretende bem-vindo; para os jovens, é uma novidade.

Imagem 2 - Aparelho para discos de vinil, fitas cassete, CDs, pendrive e rádio

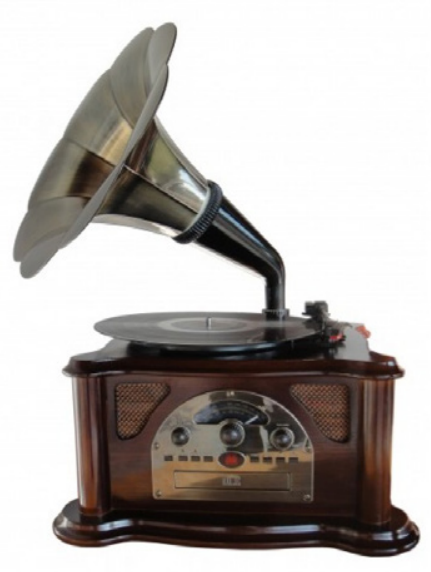

Fonte: Internet

3 Disponível em: <http://polysom.com.br/>. Acesso em: 16 out. 2014. 
Diante de toda essa ebulição de elementos retrô e vintage, estará na publicidade a mais relevante presença, tanto em propagandas que vendem outros produtos e se valem de materialidades retrô, como em produtos que por si próprios constituem-se nessas materialidades.

Essa última situação conduz ao objeto que ora se apresenta ao olhar: camisas de futebol retrô. Portanto, este artigo tem como objetivo principal, a par de teorizar o efeito retrô, investigar a presença do discurso publicitário (como manifestação multissemiótica nesse campo discursivo) e do que ele medeia como textos (camisas que podem ancorar, por sua vez, elementos verbais). Buscamos também verificar por que as camisas de futebol podem ser consideradas materialidades textuais com função discursiva que amalgamam diferentes semioses (letras, números, cores).

\section{Análise de discurso (AD) e ciências sociais}

Para fundamentar o estudo do objeto que temos em vista, selecionamos algumas categorias fundamentais da Análise de Discurso e procuramos vinculá-las a outras áreas que encampam a questão social encravada no mundo contemporâneo: ideologia, história, memória, discurso, texto, mídia.

0 objetivo primeiro da AD é mostrar como um discurso funciona, produzindo efeitos de sentido (ORLANDI, 2005). 0 destaque aqui diz respeito, efetivamente, a discurso, material simbólico, e não gramática, ou língua, ou mesmo texto - em sua organização e conteúdo específico. "A entrada no simbólico é irremediável e permanente: estamos comprometidos com os sentidos e o político." (ORLANDI, 2005, p. 9). Isso supõe desde a conversação banal do dia a dia até o tratamento 
das tecnologias de linguagem, mexendo com a ideologia e as modalidades de memória - institucional, que labora no sentido da estabilização; e memória subordinada ao esquecimento (o movimento do interdiscurso) -, num panorama sociopolítico em que tudo é disperso e provisório: o mundo, como se entende hoje, com suas práticas discursivas multissemióticas. Nessa conjuntura, é a ideologia que fornece, como dispositivo social, o que tratamos como evidências - ou naturalização daquilo que é concebido por relações de força específicas atuando na sociedade.

Como assinalado anteriormente, no fenômeno do retorno temporal, a memória tem um fundamental papel. Em que termos consideramos a memória? Tratamos dessa noção em sua inevitável historicidade, aquela de caráter social, coletivo. E é desse ponto de vista que Courtine (2006) evoca os estudos pioneiros de Maurice Halbwachs, especialmente Les cadres sociaux de la mémoire, de 1925, e La mémoire collective, publicado na França em 1951, lembrando que o autor pensava a linguagem como via de acesso privilegiada para analisar os quadros sociais da memória. A memória coletiva abrange família, grupos de todo tipo, classes sociais e se manifesta igualmente em aspectos individuais, como os sonhos.

A relação entre história e linguística, implicando a memória, está presente nas ciências da linguagem desde o final dos anos 1960, quando Pêcheux constituía interdisciplinarmente a teoria da Análise de Discurso na França com Jean Dubois, no quadro do marxismo. Ao lado disso, construía-se também o projeto de uma história da linguística (cf. COURTINE, 2006). Enfim, constatava-se uma renovação de perspectivas para o estudo da existência histórica das práticas de linguagem, trabalhando o funcionamento da memória - o que, de resto, temos observado desde sempre com a prática de reme- 
moração em todas as esferas. E a linguagem, salienta Courtine (2006, p. 9, grifo do autor), "é o tecido da memória". Portanto, em Análise de Discurso, a categoria da memória tornouse essencial, sem esquecermos que é justamente no processo político e cultural que esse tópico mostra substancialidade: rituais, esquecimentos, apagamentos, rememorações, ressurreições, fragmentação, embates, efeitos de memória em acontecimentos que despontam - no caso que examinamos, como ilustração, as camisas de futebol, o efeito de retrô neste momento de uma cultura contemporânea.

Antes de passarmos à especialização da noção de memória em $\mathrm{AD}$, situemos o conceito de memória coletiva de Halbwachs. Ele o faz em paralelo com a noção de memória individual. Estabelece, de saída, a alteridade fundamental da humanidade: "sempre levamos em nós e conosco um certo número de pessoas inconfundíveis" (HALBWACHS, [1950] 2002, p. 4) 4 $^{4}$ Assim, as lembranças para ele são coletivas, e trazidas à nossa consciência por outras pessoas, mesmo quando se trata de experiências pessoais. Com efeito, embora pareça que a memória individual se opõe à coletiva, ela não é suficiente para evocar e reconhecer lembranças, porque depende substancialmente de grupos; a memória depende de um fundamento comum: reconstruir um passado exige que haja noções comuns num grupo social - este é o cimento da sociedade.

Uma mente solitária não pode funcionar adequadamente a partir de uma consciência plena. Eventualmente, como diz Halbwachs, ao responder sua própria pergunta a respeito da possibilidade de uma lembrança ou de um ponto de vista estritamente pessoal, forjado independentemente de grupos, isso seria possível, mas seria um fenômeno excepcional, e precisa-

4 A tradução das citações em espanhol neste texto é de nossa responsabilidade. 
ria ser testado para se aceitar que a memória coletiva não explicaria todas as nossas lembranças. Por isso ele propõe níveis: a) primeiro nível da memória coletiva - diz respeito às lembranças que têm a ver com fatos e experiências de grande parte dos membros de um grupo; b) segundo nível da memória coletiva - diz respeito a lembranças compartilhadas por um número restrito de membros de um grupo. No entanto, grupos não vivem isolados; entram em relação com outros grupos, às vezes de modo permanente, outras vezes em ligações temporárias.

A ideia de que haja situações em que pensamos e atuamos livremente (individualmente) seria uma ilusão, havendo apenas uma diferença de grau, considerando as múltiplas correntes de pensamento coletivo que se cruzam em nós, produzindo estados complexos. "Diremos, de bom grado, que cada memória individual é um ponto de vista sobre a memória coletiva, este ponto de vista se transforma conforme o lugar que ocupo, e que este mesmo lugar muda conforme as relações que estabeleço com outros meios sociais." (HALBWACHS [1950] 2002, p. 6). Assim, mesmo as lembranças consideradas mais estritamente pessoais são explicadas, na perspectiva de Halbwachs, pelas trocas efetivadas em nossas relações com ambientes coletivos e suas transformações. Como se pode observar, tais proposições se aproximam bastante do que vemos em $\mathrm{AD}$ relativamente à constituição da subjetividade nas relações sociais em campos que se cruzam, especialmente atentando para a interdiscursividade (a memória discursiva, a memória da coletividade).

Halbwachs ainda apresenta - o que é relevante para nós - a relação memória coletiva/memória histórica - o que deve ajudar a compreender como é contextualizada a historicidade no corpo da AD.

A memória coletiva, embora se engendre com memó- 
rias individuais, evolui segundo suas próprias leis. A partir disso, Halbwachs distingue duas formas memoriais: memória interior (pessoal ou autobiográfica) e memória exterior (histórica). Esta apresenta o passado com uma forma esquemática, enquanto a memória pessoal tem um contexto contínuo e mais denso. A memória coletiva, no entanto, não se constitui meramente de datas e listas de fatos históricos; se assim fosse, seu papel nas recordações seria secundário. Admitindo que pontos de referência são inevitáveis, para estabelecer relações de memória, é necessário dizer também que a história não abarca todo o passado. E se o passado deixa rastros visíveis por toda parte, também deixa traços de modos de pensar e de sentir que se conservam inconscientemente, traços nem sempre lembrados, logo esquecidos.

Marcando a diferença, Halbwachs ([1950] 2002, p. 8) diz que, "se por memória histórica se entende a sucessão de eventos recordados pela história nacional, não é ela, não são marcos (quadros) que representam o essencial do que chamamos memória coletiva.". Pelo menos em dois tipos de relação se dá a distinção entre memória coletiva e memória histórica: a memória coletiva é uma corrente de pensamento contínuo, não artificial, retendo do passado aquilo que se encontra vivo ou capaz de viver na consciência de um grupo; e existem, além disso, memórias coletivas múltiplas: cada grupo tem sua própria memória, com eventos e personagens próprios. Um grupo toma consciência de sua identidade através do tempo - "é um mural de semelhanças" (HALBWACHS, [1950] 2002, p. 9) -; a história tem como marcos as formas que se diversificam, as alterações essenciais, as rupturas, ignorando intervalos de tempo em que aparentemente nada acontece além da rotina. Como a memória coletiva tem seus limites, “o que é verdadeiramente o passado para ela [a História] é o que não está mais compreendido no domínio em que se estende 
ainda o pensamento dos grupos sociais.". (HALBWACHS, [1947] 2006, p. 4, tradução nossa). Pode-se dizer que a história compõe uma memória de caráter institucional.

Para a concepção de memória discursiva desenvolvida em $\mathrm{AD}$ (sob o termo geral interdiscursividade) lembremos que a linguagem - com suas virtualidades - também compõe a memória coletiva, que por isso remete a esse manancial que é uma matriz de sentidos. Para a produção discursiva, a subjetividade, as circunstâncias no panorama social (politicamente falando) e a memória são elementos essenciais do que se concebe como condições de produção. A memória guarda saberes da ordem do discurso produzidos e mantidos, e que retornam podendo ser reconhecidos ou não; eles trazem ressonâncias, manifestam modalidades ideológicas, produzem efeitos nas novas formulações, independentemente de uma vontade expressa, com que trabalham em geral as teorias cognitivistas - a memória semântica, por exemplo (cf. ORLANDI, 2005, p. 30 et seq.). Isso significa que enquanto o interdiscurso (mas não só) sustenta formulações - o dizer em curso -, também manifesta o que não teria sido desejado nesse dizer, dado o nível de funcionamento do interdiscurso como constituinte de sentido.

Assim é que o que se manifesta (dizer) "se encontra na confluência dos dois eixos: o da memória (constituição) e o da atualidade (formulação)." (ORLANDI, 2005, p. 33). Interdiscurso, nessa linha, é historicidade - e aqui podemos associar essa formulação à distinção de Halbwachs entre memória coletiva e História: a historicidade do interdiscurso em AD remete à memória coletiva, como memória de grupos, de onde tais grupos extraem sua identificação, ainda que temporária, porque há movência. De fato, grupos diversificados sustentam memórias coletivas diversificadas, como repartições sociais do interdiscurso, que produzem efeitos diferentes (com even- 
tuais embates) em grupos diferentes (vivendo uma tradição ou ressignificando-a).

Aproveitando este momento teórico, podemos observar que as pessoas que comprariam uma camisa de clube de futebol ou que fariam comentários semelhantes ao da historieta no início de nosso texto poderiam até não fazer parte de um mesmo grupo, mas compreenderiam efeitos de sentido, em conjunto, por se filiarem ao conhecimento histórico sobre determinado campo, no caso o futebol.

Se o interdiscurso, lugar de memória (em que as vozes não têm nome) do qual, contraditoriamente, nos esquecemos, é um fundamento para o dizer, o intertexto tem um funcionamento diferente, levando-nos a um outro lugar de memória: "o intertexto restringe-se à relação de um texto com outros textos. Nessa relação, a intertextual, o esquecimento não é estruturante, como o é para o interdiscurso." (ORLANDI, 2005, p. 34). É assim que outro tipo de memória sustenta nossos conhecimentos e remete à disponibilidade: uma memória guardada, seja em arquivos, bibliotecas, museus ou em monumentos. Essa forma de memória se vincula especificamente à História, naquele sentido demarcado por Halbwachs. Na AD, remeteria à memória institucional, uma forma de combate ao esquecimento - e uma forma de mostrar que receamos deixar cair no esquecimento os eventos, o que significaria sofrer perda de identidade. Daí a grande quantidade de modos de registro disponíveis nas sociedades para funcionar como reservatórios de vida passada, passíveis de retomada, de reformulação, de ressignificação, por meio de enlaçamentos do passado. E assim chegamos ao contexto da porta que se abre para a exploração do passado nesse fenômeno chamado retrô - com suas variedades e com seus objetivos.

Porém, se a memória pode ser sustentada (historiciza- 
da), o que é feito pelas relações que uma forma de linguagem possibilita, também é preciso mostrar que, nessa organização discursiva, o modo de fazê-lo implica o trabalho do imaginário social - e por meio dessa função construímos e reconstruímos a realidade (passada, presente e também futura), atuando como posições subjetivas nas construções discursivas. "0 que significa no discurso são essas posições. E elas significam em relação ao contexto sócio-histórico e à memória (o saber discursivo, o já-dito)." (ORLANDI, 2005, p. 40). A memória coletiva sustenta, de um lado, um tipo de saber; a memória institucional (histórica) se agrega a esse saber, fornecendo alguma forma de objetividade, e assim estabelecemos o movimento de retorno ao passado ou da viagem ao futuro, com nossas utopias. Para cada lugar nenhum construímos, segundo nossas possibilidades, algum lugar.

\section{Destacabilidade e memória}

Retornamos a um ponto de nossa contextualização, para relembrar que, no processo de retornar ao passado, podemos pensar que o clima desse passado veio junto com o objeto que ressurgiu. A memória também é seletiva, e o esquecimento é sua parceira. Dissemos, então, que o que se traz do passado sofre o processo de destacabilidade, conceito que tomamos a Maingueneau como inspiração para mostrar as implicações desse processo na adaptação que fazemos. Cabe justificar essa posição.

Maingueneau (2008) parte de uma constatação: há farta circulação de enunciados curtos que podem ser olhados como fórmulas e geralmente são conhecidos por grande número de pessoas, tais como citações de grandes autores e máximas filosóficas que funcionam de modo autônomo; algumas, po- 
rém, são citadas "para marcar um posicionamento específico que se opõe implicitamente a outros." (MAINGUENEAU, 2008, p. 75). Tais fórmulas, em grande parte, foram destacadas de seus textos originais e passaram a um uso independente; porém, nem todo material textual pode ser destacado: algumas propriedades são exigidas para seu funcionamento independente. Por exemplo: a máxima heróica, que tem um caráter generalizante e é percebida como imemorial, é um enunciado "antigo de direito, novo de fato" (MAINGUENEAU, 2008, p. 77), e por isso torna-se monumentalizado, permitindo a retomada ilimitadas vezes, e se liga ao próprio enunciador e, a partir dele, aos outros, como uma prescrição. No Cid, de Corneille, Maingueneau busca esta máxima, posta na boca do herói chamado Rodrigo: "A coragem não espera a idade.". As fórmulas filosóficas têm também o caráter de destacabilidade em uma ou outra passagem dos textos em que aparecem, funcionando como uma síntese da discussão; seja "A religião é o ópio do povo.", enunciada por Marx. Recolhemos mais duas, para ilustração, desta vez das máximas latinas: "Multos timere debet quem multi timent." (Quem por muitos é temido deve temer a muitos) - Sêneca, Naturales quaestiones; "Factum ábiit, monumenta manent." (O fato passou, os monumentos se perpetuam) - Ovídio, Fastos (cf. BUSARELLO, 1998, p. 235 e 238).

Apenas para situar o contexto da categoria de destacabilidade em Maingueneau, acrescentemos que o autor a insere na noção de sobreasseveração, que caracteriza um enunciado relativamente breve, em posição relevante em um texto, em que adquire estatuto de condensado semântico - realizando uma sedimentação no discurso -, e que representa uma tomada de posição num contexto de conflito de valores, implicando uma "amplificação da figura do enunciador" (cf. MAINGUENEAU, 2008, p. 82). Esse fenômeno, diz ele, é particularmente 
abundante nas mídias, que utilizam frequentemente slogans, retomados como citações.

Por que uma manifestação de retrô implicaria a destacabilidade? É que, mobilizando a memória, especialmente a coletiva, veremos o despertar de um passado mais ou menos recente - em termos de formas, produtos ou pensamentos - como rememoração. E, como estamos nos referindo especificamente a produtos vendáveis, trata-se de um destaque que pretende sobrevalorizar aquilo que é ressuscitado por suas qualidades - trate-se de retrô propriamente, ou de vintage, com sua carga de valor aumentada.

Seja por nostalgia, seja por receio de perda da memória, neste caso há uma meta específica: pela publicidade, a venda daquilo que possa tornar-se objeto de desejo. Com esse investimento, procura-se também trabalhar o clima em que, supostamente, os objetos surgiram. No caso das camisas de futebol, especialmente considerando a realização da Copa do Mundo de futebol no Brasil em 2014, é compreensível que se trabalhe o que websites de venda têm chamado de 'resgate' de momentos históricos do futebol com, além de camisas retrô (que são o carro-chefe), produtos como bonés, bolas, canecas e livros com a história dos clubes. Alguns oferecem produtos com tecidos que se aproximam daqueles utilizados nas camisas antigas ou com o mesmo material utilizado em sua confecção, além das cores, modelagem, escudos, números e letras. 0 que podemos ver é que um evento histórico impulsiona o surgimento de novas modalidades discursivas, mobilizando a memória coletiva e a memória discursiva em geral, especialmente considerando a agilidade do mercado, que disso se aproveita em função da propaganda que vende, selecionando do passado aquilo que pode mobilizar multidões ao apelar para o imaginário. É uma espécie de grande metáfora, que mobiliza não só campos sincrônicos, mas mexe com a temporalidade dos eventos e suas imagens. 


\section{Lembrança, esquecimento, simulação}

Todo esse processo publicitário de retorno ao passado mostra, de algum modo, que algo se traz de volta e algo se esquece, visto que há um recorte. Sempre se destaca algo que possa comover, alimentar a nostalgia, vender. Isso nos remete a um trabalho importante que merece ser rememorado: Simulacros e simulação, de Jean Baudrillard. Nessa obra, o filósofo alega: "Dissimular é fingir não ter o que se tem. Simular é fingir ter o que não se tem." (BAUDRILLARD, 1991, p. 9). Simulação, para o autor, se opõe a representação:

Esta [a representação] parte do princípio de equivalência do signo e do real (mesmo se esta equivalência é utópica, é um axioma fundamental). A simulação parte, ao contrário da utopia, do princípio de equivalência, parte da negação radical do signo como valor, parte do signo como reversão e aniquilamento de toda a referência. (BAUDRILLARD, 1991, p. 13, grifo do autor).

Seguindo a proposta de Baudrillard, temos, por exemplo, fotos de simulação ${ }^{5}$ nas quais Matthew Albanese projeta em laboratório e fotografa paisagens simuladas em miniatura, com um efeito impressionante de realidade. Ainda nesta perspectiva, o site Tramp mostra o que cartões postais ${ }^{6}$ escondem, a partir de um bom enquadramento e manipulação digital. Portanto, simula-se um mundo, recorta-se, seleciona-se. Descarta-se o que deve ser secundarizado. Nesses casos, procede-se a uma romantização do que é trazido ao presente, com um efeito de

5 Disponível em: <http://www.tramp.com.br/arte/fotografias-impressionantes-de-paisagens-em-miniatura-por-matthew-albanese/>. Acesso em: 04 nov. 2014.

6 Disponível em: <http://www.tramp.com.br/turismo/pontos-turisticos-famosos-mostrados-numa-perspectiva-nao-tao-bonita/>. Acesso em: 04 nov. 2014. 
magia. A esse propósito, podemos lembrar o que disse Roland Barthes sobre a imagem fílmica, em "Ao sair do cinema":

A imagem fílmica (incluindo o som) é o quê? Um engodo. [...] A imagem está ali, diante de mim, para mim: coalescente (o seu significante e o seu significado bem fundidos), analógica, global, pregnante; é um engodo perfeito: precipito-me sobre ela como um animal sobre o pedaço de trapo "semelhante" que lhe estendem [...] (BARTHES, [1975] 2004, p. 431, grifo do autor).

Com um pessimismo impositivo, Baudrillard (1991, p. 59-65) defende a tese de que o cinema (e é essa a mídia que ele vai usar como exemplo em sua argumentação) não cria mais nada senão simulacros de produções de outrora. Vale salientar que Baudrillard escreveu esses textos durante a década de 1970. Portanto, há duas considerações a se fazer: a) por um lado, os exemplos que ele utiliza, por mais semelhantes que sejam aos exemplos atuais, são de fato da década de 1970. Aponta, por exemplo, a possibilidade de "voltar a fazer filmes mudos, melhores, sem dúvida" (BAUDRILLARD, 1991, p. 62), fato que acontece atualmente, tendo-se como exemplo emblemático o filme francês $O$ Artista (preto e branco, mudo), que ganhou o Oscar de melhor filme estrangeiro em 2012; b) por outro, as projeções que ele fez em 1981 se confirmaram e até mesmo se potencializaram, pois atualmente, em vários campos (publicidade, cinema, culinária, música), há a afirmação do "grande traumatismo [...] esta agonia dos referenciais fortes, a agonia do real e do racional que abre as suas portas para uma era de simulação." (BAUDRILLARD, 1991, p. 60, grifo nosso).

Os argumentos de Baudrillard são de que a história não mais existe (ele utiliza os termos 'póstumo' e 'fósseis'), exemplificando o fato de que as produções cinematográficas da época - também as televisivas - nada têm de novidade. 
São retrô no sentido fotográfico que assumem, e a presença da história no cinema "não tem o valor de uma retomada de consciência, mas de nostalgia, de um referencial perdido." (BAUDRILLARD, 1991, p. 61).

Baudrillard (1991, p. 60) afirma (lembrando novamente que escreveu na década de 1970): "É neste vazio que refluem os fantasmas de uma história passada, a panóplia dos acontecimentos, das ideologias, das modas retro." [sic]. Ao final do ensaio, ao passo que propõe que o cinema poderia "colocar todo seu talento, toda sua técnica" (idem, p. 65) na criação de coisas novas, o autor também pinta um cenário tétrico ao afirmar que esse mesmo cinema liquidou a história, os mitos, e "apenas ressuscita fantasmas e aí se perde ele próprio." (idem, p. 65).

Se nem mesmo a história, como nos lembra Gagnebin (2006, p. 40), reportando-se a Walter Benjamin, escapa da "impossibilidade epistemológica de tal correspondência entre discurso científico e 'fatos' históricos, já que estes últimos adquirem seu status de 'fatos' apenas por meio de um discurso que os constitui enquanto tais", que diremos da memória coletiva, especialmente daqueles que escavam o passado com interesse mercantilista? Lembrando Halbwachs, Gagnebin (2006, p. 97) afirma que, por não estarmos mais inseridos em uma tradição de memória viva, comunitária e coletiva, o sentimento forte da caducidade da existência e das obras humanas nos leva a "inventar estratégias de conservação e mecanismos de lembrança" tais como organização de colóquios, livros, números especiais, álbuns de fotografias...

Davallon ([1983] 1999), num estudo sobre a imagem na perspectiva da memória, remete ao problema da manutenção da memória social quando, contemporaneamente, parece que toda a memória pode ser registrada em arquivos físicos. Como os acontecimentos que marcam as comunidades po- 
dem inscrever-se no tecido social, no sentido em que Halbwachs considerava a formação da memória coletiva, produzindo coesão? Tomando a memória como fato societal e como fato de significação, Davallon pensa nas imagens e retoma a noção de memória coletiva desse autor, que exige que acontecimentos ou saberes façam sentido para um grupo e possam ser lembrados por muito tempo por esse grupo em suas relações intersubjetivas. Claro, não estamos aqui no nível da memória histórica, tal como avaliou Halbwachs e vimos acima. Davallon considera que a distinção proposta por Halbwachs (1999, p. 26) "nos introduz acima de tudo em uma problemática dos objetos culturais considerados como operadores de memória social.". Com isso ele pensa em como seria pertinente a possibilidade "de 'casar' história e memória coletiva: de entrecruzar, de aliar a resistência ao tempo que caracteriza uma [a história] e o poder de impressão - vivacidade - da outra [a memória coletiva]." (DAVALLON, 1999, p. 26). Um acontecimento poderia entrar na corrente da história, memorizado, e ao mesmo tempo ser um "elemento vivo de uma memória coletiva” (p. 26). É a esta forma de memória, mais especificamente, que Davallon chamaria de memória societal.

Isto posto, Davallon sugere que a imagem poderia ser um operador de memória social, por sua capacidade de funcionar, digamos, como uma forma de representação e como reserva de relações sociais, causando impressão por sua força simbólica. A publicidade, associando imagem e enunciado linguístico, permite tornar presentes "as qualidades de um produto e conduzir assim o leitor a se recordar de suas qualidades" (ibid, p. 28), bem como levá-lo a representar um lugar como consumidor. A síntese disso seria, na perspectiva de Davallon, a verificação da eficácia simbólica de uma produção cultural, considerando o processo de interpretação a que ela obriga. 
Após essa necessária tematização das categorias discursivas em seu cruzamento com as ciências sociais, passemos a aspectos relevantes da publicidade para nossos propósitos.

\section{Publicidade}

Um dos principais domínios discursivos existentes é a publicidade, atuante desde a compra de um doce até a de um carro ou uma casa, passando pela promoção de serviços, instituições e pessoas. Conforme Baudrillard (1991, p. 115), “a forma publicitária impôs-se e desenvolveu-se à custa de todas as outras linguagens, como retórica cada vez mais neutra.".

A publicidade - ou discurso publicitário - não existe per se. Fairclough (1992) afirma que o discurso publicitário coloniza outros campos. Essa noção é compartilhada e amplamente aceita na Análise (Crítica) do Discurso de linha anglo-saxã. Apesar de não sermos partidários desse postulado, é inegável que "certas características" de algo que chamamos discurso publicitário acabam por aparecer em maior ou menor escala em diversos outros domínios discursivos, notadamente não promocionais. É o caso, por exemplo, da autopromoção tão comum em currículos, blogs pessoais, etc. Queremos também nos vender (até mesmo em sites de relacionamento).

Já Baudrillard postula que a publicidade está em tudo, mas não está em nada ao mesmo tempo. Para o filósofo, as linguagens absorvem-se na publicidade. Não é a publicidade que as absorve, elas - formas culturais originais, linguagens - absorvem-se (grifo nosso). 0 modo de expressão da publicidade é efêmero, pois "não tem profundidade, é instantâneo e instantaneamente esquecido." (BAUDRILLARD, 1991, p. 113).

No sentido mais clássico de publicidade, 'imperativa' e 
'impositiva' são adjetivos que vão ao seu encontro. A publicidade "está em todo lugar. Em todo instante." (MENEGUIN, 2009, p. 17). Somos compelidos - mesmo que não tenhamos consciência disso - a comprar, consumir, usufruir serviços, a partir das estratégias discursivo-textuais que diversas propagandas utilizam. Todo esse apelo emocional e psicológico acaba por criar algo que poderíamos chamar de uma 'pseudonecessidade' de produtos e serviços.

Somos bombardeados diariamente por um número grandioso de propagandas que são constituídas, sobretudo, por elementos não verbais. Com o advento da televisão colorida e posteriormente com a internet, a utilização, por vezes exacerbada, de imagens, cores e recursos não verbais em geral é uma constante na publicidade. Gonçalves (2006, p. 31) aponta que "há uma tendência, na publicidade atual, de produzir mensagens publicitárias de tal forma icônicas, que o texto linguístico é [quase] deixado de lado, resumindo-se a chamadas e slogans.".

Esse fenômeno está diretamente ligado à efemeridade, pois o turbilhão de imagens e cores a que somos expostos diariamente faz com que, se fizermos o exercício de tentar lembrar as propagandas a que temos acesso do caminho de nossa casa até o trabalho, provavelmente rememoraremos um número ínfimo delas em relação ao que de fato vimos/lemos. Corrobora o fato de que a publicidade trabalha cada vez mais imagens e menos texto verbal o trabalho de Campos (2005), no qual são analisadas propagandas da Coca-Cola. Por meio de um exame diacrônico, a pesquisadora chega à conclusão de que uma peculiaridade da propaganda de 1989 (em relação a uma de 1953) é que algumas décadas depois a imagem aparece em detrimento do verbal. No início, diz ela, tendo em vista a necessidade de argumentar com dados comparativos, preços e outras informações, o texto verbal tinha mais importância que o pictórico, que funcionava como complemento 
- o que é uma forma de dizer: com as palavras eu convenço você, e com as imagens eu persuado você; no caso, "uma fonte cristalina de pureza" remete a uma portentosa cachoeira (cf. CAMPOS, 2005, p. 947). Isso não significa, entretanto, que a materialidade icônica meramente prescinda da materialidade verbal.

No caso deste trabalho, pensar em termos de semioses não verbais é imprescindível, pois entendemos que as camisas de futebol são textos multissemióticos. São multissemióticos porque têm em sua constituição recursos de diferentes semioses: linguagem verbal, cores, escudos (imagens), uma tipografia peculiar nos números. Além disso, trata-se, efetivamente, de pôr aquele objeto semiotizado no mundo concreto, ao alcance de corpos em que o desejo se instale. Isso deve produzir uma sensação análoga àquela descrita por Barthes (2004) relativa à imagem fílmica.

Para esse último ponto, é conveniente trazer a discussão de Cook (1992) sobre elementos linguísticos e paralinguísticos, tendo por base a Semiótica Peirciana. Cook adapta, para a interpretação do discurso publicitário, conceitos como índice e ícone.

Cook inicia a explicação e sua tipologia sobre o double channel' (linguístico/paralinguístico) diferenciando a literatura da publicidade. Em suma, na literatura a iconicidade é construída por meio de significações (sonoridade, aliterações) do texto ou pela disposição das palavras na folha impressa, como é o caso dos poemas concretistas. 0 paralinguístico não se dá pela forma das letras em si, pois "a forma das letras não é tão importante" (COOK, 1992, p. 77). Mas a publicidade explora enormemente o paralinguístico.

Eis algumas maneiras, na tipologia de Cook, pelas quais o paralinguístico ocorrerá: a) com a disposição das palavras

7 Preferimos não traduzir esse termo. 
em si (os dizeres de uma loja de materiais de construção são dispostos de modo a formar um telhado na imagem da propaganda); b) pela forma da letra, como nos exemplos de logotipos que Cook apresenta: Alitalia - cuja letra inicial 'A' imita a cauda de um avião; os cigarros Dunhill com letras prolongadas simulando uma carteira de cigarros; c) com ícones e símbolos conectados; d) signos arbitrários e ícones conectados; e) escrita que provoca comportamento icônico; f) evocação do ânimo/humor por meio da tipografia.

Importa frisar que, apesar de Cook afirmar que "muitos nomes de marcas famosas são inextricavelmente conectados com o tipo da letra na qual estão escritos" (COOK, 1992, p. 84), ele também assume que "é difícil categorizar esse tipo de significação usando os termos semióticos [de Peirce]." (p. 85). Essa significação se refere à utilização de um tipo específico de letra para representar um produto, seja uma marca conhecida, ou um traço como o caligráfico para representar informalidade, ou o caligráfico mais simétrico para representar um documento antigo e afins. Ou ainda um excesso de serifas, como nos tipos góticos, para lograr associação com um traço de antiguidade. Difícil por parecer que há uma arbitrariedade nas significações exemplificadas acima, mas se recorrermos às noções sobre memória apresentadas na seção anterior, teremos uma possibilidade de discussão sobre os elementos gráficos e verbais constituintes das camisas de futebol retrô, os quais apresentaremos abaixo, complementando a análise que, aqui e ali, já introduzimos em meio à discussão teórica.

\section{A materialidade retrô em camisas de futebol}

Como constatado e exposto nas seções anteriores, mate- 
rialidades discursivas que em sua concepção remetem ao passado têm frequentemente o valor de fino, requintado, confiável, bom, tradicional, o que já deu certo. A publicidade se vale de elementos retrô, evidenciando o que poderíamos chamar de nostalgia, que figura como elemento de agregação persuasiva.

Tentaremos contextualizar o tipo de retroação e momentos em que as camisas em estilo retrô ganharam um halo de sucesso para justificar a busca no passado. Os vários exemplos rememorados/retextualizados por meio das camisas retrô nos websites visitados são de momentos de glória dos clubes, épocas em que foi campeão, contou com jogadores marcantes e admirados até hoje etc., e não "qualquer época". Vemos, então, de um lado, fatos da ordem do acontecimento (grandes vitórias) com registro histórico em várias semioses, e a estimulação da memória coletiva, na forma de publicidade, no sentido em que Davallon fala da memória coletiva, compondo, em junção com a história, a memória societal.

A imagem na publicidade é um operador de memória, e ainda assim, nesse nível, é uma imagem; sua "mágica", porém, não fica no nível do olhar, porque, diferentemente do produto contemporâneo em seus próprios termos, a camisa vista promete uma concretude e valor simbólico, e, em alguns casos, a verificação táctil de um tecido fabricado "como antigamente". Isso recria um mundo como se fora um halo em torno da peça - ilusão necessária de uma viagem no tempo. As camisas simulam, por assim dizer, o real de um passado (que só pode voltar por simulação) para satisfazer o desejo, a utopia da presença romântica duradoura, memória de um referencial perdido - entrando no circuito de uma real co-memoração. Essa possibilidade é que deve fazer, como explicitou Barthes com relação ao cinema, que tais objetos sejam buscados e comprados, mesmo a um alto preço. Ademais, tais peças, como em 
geral as que compõem os uniformes, não são apenas camisas; nomeadamente, elas têm um estatuto social maior.

Eis alguns exemplos.

Presente em vários websites, está a camisa da seleção brasileira de futebol campeã de 1970 no México (memória de mais de quarenta anos). Não raro são os momentos em que a grande mídia - e ecoado desde o discurso de populares até a análise de críticos de futebol - brada que a melhor seleção brasileira de futebol foi a de 1970. Por vezes esse título é dado à seleção de 1982; contudo, o fato de não ter ganhado um título mundial não lhe rende as 'boas lembranças' que a seleção de 1970 traz. Ser protagonista do tricampeonato, contar com Pelé no time, gols memoráveis e lances que são lembrados até hoje pela crônica esportiva fazem dessa camisa hors concours entre as que estão à venda nos websites analisados. Até mesmo os "não entendidos" de futebol, ao olharem a camisa, talvez por sua vasta veiculação na mídia durante anos, construirão um sentido positivo em relação a um 'passado glorioso' do futebol brasileiro, encenado como uma era de heróis; a camisa é não apenas relembrada, como uma peça de museu, mas vestida e, portanto, sentida, produzindo aquele efeito de que fala Barthes. 0 ícone se presta, então, para articular ao corpo o sentido criado a partir da memória. Além do mais, tais elementos, relembrando Davallon, funcionam como um "operador de memória social", como reserva de relações sociais, por sua força simbólica e, no caso dos produtos, não apenas por sua força simbólica, mas pela possibilidade de 'estar na pele de', embalando-se em peças como estas para ficar além da imaginação.

Outro elemento simbólico está presente aí, de caráter heráldico, herdado da Idade Média e influente ainda hoje: o brasão, presente em marcas e logotipos, que falam de tradi- 
ção, nobreza, qualidade, como dispositivo de identificação ${ }^{8}-$ no caso, da CBD, e plantado na peça do lado do coração. Note-se que no campo verde do escudo aparece uma cruz, que talvez tenha apenas valor estético ${ }^{7}$.

Imagem 3 - Camisa retrô do Brasil - 1970

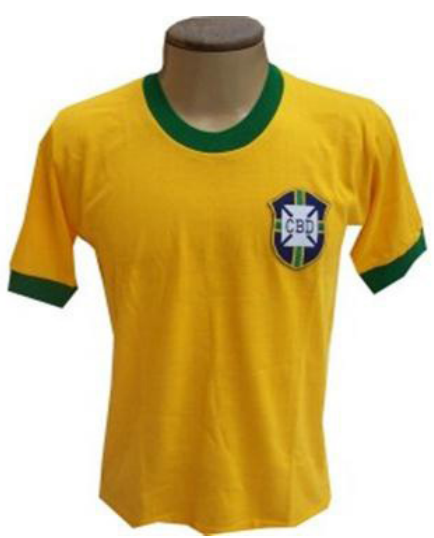

Fonte: Internet ${ }^{9}$

O clube de futebol com maior número de torcedores no Brasil não poderia ficar fora desses websites. As camisas retrô do Flamengo à venda são em sua maioria da década de 80 . Nessa década o clube conseguiu três títulos brasileiros e contava com jogadores que fazem parte do cânone brasileiro de craques como Zico.

8 Dependendo dos tempos e dos contextos históricos, as marcas de identificação também manifestavam a desonra, a servidão, a exclusão, inclusive gravadas na própria pele, como a marcação outrora feita com ferretes em escravos. Seriam a outra face da honra, do orgulho.

9 Disponível em <http://camisasdefutebolretro.com/product.php?id_product=70>. Acesso em: 13 out. 2014. 
Imagem 4 - Camisa retrô do Flamengo - década de 80

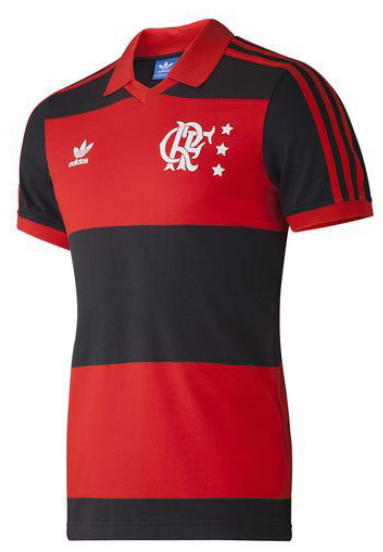

Fonte: Internet ${ }^{10}$

A camisa acima aparece no site com um pequeno texto de apresentação, o qual explicita alguns elementos persuasivo-nostálgicos que estamos advogando neste trabalho:

Inspirada no período em que o Flamengo foi mais vitorioso em sua história, a década de 80 , a Adidas faz uma homenagem a essas glórias e lança a Camiseta Retrô Flamengo. Com as cores características do Rubro-Negro, esse item é indispensável para o torcedor. [Logotipo Adidas no lado direito do peito.] (grifo nosso) ${ }^{11}$.

Além da obviedade de termos como glória, vitorioso e retrô, em relação aos argumentos apresentados até aqui, a expressão "lado direito do peito" deixa espaço para que o brasão

10 Disponível em <http://www.adidas.com.br/camiseta-retro-flamengo/M31405_360.html?gclid=CKqxn-2W4b8CFYMF7Aody0EARA >. Acesso em: 13 out. 2014.

11 Disponível em: <http://www.adidas.com.br/camiseta-retro-flamengo/M31405_360. html?gclid=CKqxn-2W4b8CFYMF7Aody0EARA >. Acesso em: 13 out. 2014. Note-se também o valor de venda da peça: $\mathrm{R} \$ 299,90$. 
MEMÓRIA, NOSTALGIA E PUBLICIDADE: O CASO DAS CAMISAS RETRÔ DE FUTEBOL

do time com suas letras caligráficas fique do lado esquerdo, do coração. As letras caligráficas dos brasões não são exclusividade das camisas retrô. Aparecem em camisas de clubes de futebol em geral. Contudo, há nesse tipo uma relação com o discurso da tradição que se constrói. Portanto, o item caligráfico também é ícone: mostra-se seu uso não apenas como números e letras quaisquer, mas como operadores de memória eles remetem a tempos e espaços de sua criação e articulação com cores e modelagem. Um leitor e comprador, por exemplo, declara ser o produto uma reconstituição do 'manto sagrado'!

Assim, ao imaginário do clube de futebol vencedor, aludindo didaticamente a uma determinada época, é oferecida uma referência de memória em relação ao ano. Ou seja, não somente o texto não verbal em suas cores, brasões etc., mas também elementos verbais são usados nesse jogo, como podemos ver nos exemplos que seguem:

Imagem 5 - Camisas retrô com números e palavras alusivos a um determinado ano de um título do clube
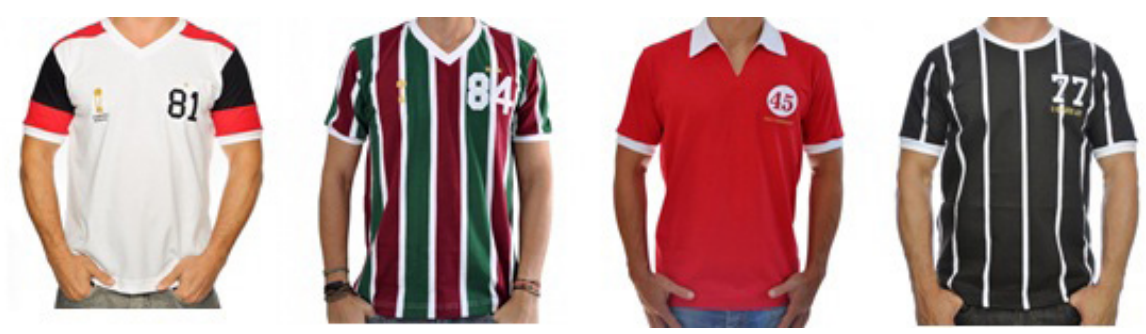

Fonte: Internet ${ }^{12}$

12 Disponível em <http://www.retromania.com.br/loja/index.php/rubro-negro-rj1981-mundial.html\#>

<http://www.retromania.com.br/loja/index.php/tricolor-1984-listrado.html\#> <http://www.retromania.com.br/loja/index.php/camisa-retro-colorado-1945.html\#> <http://www.retromania.com.br/loja/index.php/preto-e-branco-away-1977.html>. Acesso em: 13 out. 2014. 
Além do afirmado acima em relação ao Flamengo, em 1981 esse clube foi campeão carioca e mundial. O Fluminense foi campeão carioca e brasileiro em 1984. Na década de 40 e 50 o clube gaúcho Internacional foi apelidado de "Rolo compressor" (a expressão encontra-se logo abaixo do número 45 na camisa) por ter tido várias vitórias e títulos. Em 1945 foi hexacampeão gaúcho invicto. Em 1977, o clube paulista Corinthians venceu o campeonato estadual após muitos anos sem nenhum título. Portanto, a expressão "o grande ano" abaixo do número 77 reconstrói a história e lhe atribui sentido.

Vale a pena ressaltar que, apesar do apelo retrô, ao memorável, não é deixada de lado a ênfase na qualidade atual dos produtos: "Qualidade Liga Retrô. Visual Retrô. Tecido 100\% algodão de alta qualidade. Um belo card numerado contendo a foto e contando a história da camisa em questão acompanha o produto (Grátis) ${ }^{13}$."

Podemos dizer que, conforme a noção de imaginário social - visto acima -, o resgate do passado via ideia de retrô simula o clima de um fato, romantizando-o pelo processo de destaque com uma sedimentação semântica no discurso - porque se rememora o que havia de melhor, ou o que se imaginava ser o melhor, algo que merece ser monumentalizado. A publicidade recria 'algum lugar', aquele que, em razão de recursos persuasivo-nostálgicos, vai produzir um efeito de valorização.

Queremos agregar a essa análise uma proposta de tipologia (ainda não sofisticada) para o que chamamos Discurso da Tradição Persuasiva, caracterizando as camisas retrô de futebol a partir dos tipos apresentados.

Uma série de processos, retomada de hábitos e expressões, aponta para o tradicional como um valor em si. Ou seja,

13 Disponível em: <http://www.ligaretro.com.br/comemorativas/rolo-compressor/rolocompressor-1945.html>. Acesso em: 13 out. 2014. 
não estão relacionados diretamente à venda ou ao campo publicitário. Seriam exemplos os discursos sobre alimentação saudável, partos humanizados, ou escolha de nomes tradicionais para os filhos (bíblicos, por exemplo). Todas essas manifestações não entrariam nessa tipologia, pois não são a Tradição com propósitos persuasivos. No entanto, mesmo essas, quando relacionadas à promoção de produtos e serviços, poderiam ser categorizadas dentro do que se apresenta a seguir:

a) Retrô pele - A manifestação retrô está na composição de um produto inovado, tecnologicamente falando, mas imitando traços de um antigo: refrigeradores, toca-discos, telefones, óculos, e camisas de futebol, que olhamos mais de perto neste trabalho.

b) Retrô estratégico - Característico da publicidade, que se vale de elementos retrô para a venda de determinados produtos que não têm nada de antigo em sua composição e fabricação: cervejas que trazem no rótulo o ano suposto de início de fabricação, o famoso "desde...", a utilização de tipografia que remete ao passado, alusão a um determinado personagem antigo de TV ou da literatura. Há empresas que, além de utilizarem elementos retrô em propagandas, também criam produtos que remetem ao passado, tal como o retorno de refrigerantes em garrafas de vidro. Às vezes, junto ao discurso da sustentabilidade está um retrô que quer vender (a sustentabilidade exige meios mais dispendiosos).

c) Retrô mimético - A metáfora da mimese aqui está relacionada à imitação do processo de produção e do produto em si. Diz respeito a produtos fabricados conforme técnicas antigas ou com técnicas novas, mas reproduzidos exatamente como o eram antigamente: ladrilhos, fitas cassete, discos de vinil, filmes e animações feitas em preto e branco ou sépia, ou 
ainda gravadas em película, fabricação de cervejas artesanais.

d) Vintage - Este é o caso de um produto que adquire o status de objeto de arte (ou cult, como normalmente é visto). 0 produto é antigo em si, ou seja, foi elaborado e fabricado há muitos anos, mas volta a ser utilizado e consumido. São exemplos desse subtipo roupas antigas, móveis com madeira de demolição, discos de vinil, desenhos animados produzidos em décadas passadas que voltam à televisão (ex. nos canais Gloob, Tooncast), filmes antigos (ex. nos canais TCM e Telecine Cult).

Em suma, a tentativa de construção da tipologia do Discurso da Tradição Persuasiva apresenta quatro subtipos, sempre relacionados à venda e promoção de produtos e serviços: Retrô pele, Retrô estratégico, Retrô mimético e Vintage.

Com base nesta proposta, os exemplos recolhidos a partir dos sites analisados apontam para as camisas retrô de futebol como Retrô pele, tendo em vista a historicização de momentos/épocas de glória e também permitirem a própria sensação tátil, recriando o passado; e ainda seriam manifestação de Retrô mimético quando sua produção é feita com materiais da época em questão (ex.: camisas de algodão no lugar dos atuais tecidos sintéticos).

\section{Considerações finais}

Neste artigo propusemos uma discussão com foco no fenômeno designado como retrô, não atual, mas atualizado em razão de sua recorrência em vários campos na atualidade, especialmente na publicidade, marcando um período prenhe de configurações em que materialidades se cruzam para oferecer uma espécie de espetáculo social em que a memória coletiva 
trabalha. Para teorizar o fenômeno e posteriormente exemplificá-lo, fazendo uma leitura discursiva, usamos coordenadas da Análise de Discurso dita de linha francesa, conjugadas a noções de ciências sociais (Filosofia, Sociologia) que se voltam para a análise de elementos da cultura. Essa conjugação e consequente diálogo da AD com outros postulados, desde que não contraditórios, aponta, em nosso olhar, possibilidades profícuas para pesquisas vindouras.

O discurso publicitário - como manifestação multissemiótica -, mediando esse tipo de renovação de valores históricos, compõe propagandas não somente com certos valores de um passado recente para creditar produtos ou serviços em geral, mas também medeia especialmente a exposição de produtos fabricados com certas características retrô, reavivando periodicamente (e em função de certos objetivos) laços sociais de pequenos grupos ou de grupos amplos, prometendo um contato emocional às vezes bem táctil, como no caso de vestimentas como as camisas de futebol.

Teorizando a linha de efeitos do retrô, exploramos noções como discursividade, memória (coletiva, histórica), história, imagem, instâncias da publicidade, para mostrar como uma vestimenta específica se apresenta como uma materialidade que impregna valores que, revividos, produzem um efeito de agregação social e trazem um passado de maneira concreta, como uma viagem no tempo - sonho de todos em algum momento e por motivos específicos. Se o presente, embora 'forçado' a estender-se, é sentido como um átimo, eterna passagem segundo a segundo, em que o 'novo' só dura até a próxima inovação, que vem célere em se tratando de produtos e serviços, o apelo ao passado ou ao futuro pode dar a sensação de ligação e de identidade - embora sempre fugaz. Produzir o novo com o velho não é apenas inevitável, mas constitui- 
se em busca que não nos desatrele da comunidade. 0 clima do passado não ressurge inevitavelmente, porque também esquecemos, e a conjunção esperada é, então, ilusória - mas isso se torna secundário quando a memória está em transe.

0 que fazemos, então, nesse processo, é aquilo que teorizamos com inspiração em Maingueneau (2008): 'destacamos' um recorte do passado para usá-lo de maneiras diversas: em nossa vida cotidiana ou para induzir à compra de objetos de desejo capazes de fornecer revivescência e emoção, num jogo discursivo em que o retrô constitui-se a partir de recursos persuasivo-nostálgicos.

Trabalhamos também com a memória discursiva tal como desenvolvida na Análise de Discurso - na forma de interdiscursividade - como um manancial de possibilidades para uso geral e específico, e do qual nos servimos recortando itens e esquecendo outros para a produção de sentidos a partir desses saberes, com todas as suas ressonâncias. Interdiscurso implica historicidade.

Retomando a noção de imaginário social no quadro da Análise de Discurso, entendemos que o resgate do passado via ideia de retrô simula o clima de um acontecimento destacado, romantizando-o para torná-lo um monumento. Nesse processo, podemos dizer que a publicidade tem tido um papel imensamente valorizado - como vimos na exemplificação com as camisas de futebol.

\section{REFERÊNCIAS}

BARTHES, R. Ao sair do cinema. In 0 rumor da língua. São Paulo: Martins Fontes, [1984] 2004. p. 427-433. 
MEMÓRIA, NOSTALGIA E PUBLICIDADE: O CASO DAS CAMISAS RETRÔ DE FUTEBOL

BAUDRILLARD, J. Simulacros e simulação. Lisboa: Relógio d'Água, 1991.

BUSARELLO, R. Máximas latinas para o seu dia a dia. Repertório de citações, provérbios, sentenças e adágios tematizados e traduzidos. Florianópolis: Ed. do autor, 1998.

CAMPOS, A. L. F. de. 0 gênero publicitário: um enunciado relativamente estável? UNESP- FCLAR. Estudos Lingüísticos, Araraquara, XXXIV, p. 944-949, 2005.

COOK, G. The discourse of advertising. London: Routledge, 1992.

COURTINE, J.-J. 0 tecido da memória: algumas perspectivas de trabalho histórico nas ciências da linguagem. Polifonia, Cuiabá, v. 12, n. 12(2), p. 1-13, 2006.

DAVALLON, J. A imagem, uma arte da memória? In ACHARD, P. et alii. Papel da memória. Campinas: Pontes, [1983] 1999. p. 23-34.

FAIRCLOUGH, N. Discourse and social change. Cambridge: Polity Press, 1992.

GAGNEBIN, J. M. Lembrar escrever esquecer. São Paulo: Editora 34, 2006.

GONÇALVES, E. M. Propaganda \& linguagem: análise e evolução. São Bernardo do Campo: Universidade Metodista de São Paulo, 2006.

HALBWACHS, M. Fragmentos delamemoria colectiva.Selección y traducción Miguel Algel Aguilar D. Athenea Digital, n. 2, p. 1-11, Otoño [1950] 2002. Disponível em: <http://www.raco. cat/index.php/Athenea/article/download/34103/33942>. Acesso em: 10 out 2014. 
. La mémoire collective et le temps. Edição digitalizada por Jean-Marie Tremblay. [1947] 2006. Disponível em: <http://classiques.uqac.ca/classiques/Halbwachs_maurice/ memoire_coll_et_le_temps/memoire_coll_et_temps.pdf>. Acesso em: 10 ago. 2015.

MAINGUENEAU, D. Citação e destacabilidade. In . Cenas da enunciação. Tradução de S. Possenti e M. C. P. de Souza-eSilva. São Paulo: Parábola, 2008. p. 75-92.

MENEGUIN, A. M. P. L. Duas faces da publicidade: campanhas sociais e mercadológicas. São Paulo: Annablume, 2009.

ORLANDI, E. P. Análise de Discurso: princípios \& procedimentos. 6. ed. São Paulo: Pontes, 2005.

RETRO. In OXFORD Dictionaries. Oxford University Press, 2014. Disponível em: <http://www.oxforddictionaries.com/ us/definition/american_english/retro>. Acesso em: 03 nov. 2014.

VINTAGE. In OXFORD Dictionaries. Oxford University Press, 2014. Disponível em: <http://www.oxforddictionaries.com/ us/definition/american_english/vintage>

Acesso em: 03 nov. 2014.

\section{Websites do corpus}

<http://camisasdefutebolretro.com>

$<$ http://www.adidas.com.br/originals-camisa_de_futebol_ retro>

$<$ http://www.ligaretro.com.br>

<http://www.retromania.com.br> 
MEMÓRIA, NOSTALGIA E PUBLICIDADE: O CASO DAS CAMISAS RETRÔ DE FUTEBOL

Artigo recebido em dezembro de 2014 e aprovado em junho de 2015.

Disponível em: http://seer.fclar.unesp.br/casa 